\title{
Influence of mesoscale urban morphology on the spatial noise attenuation of flyover aircrafts
}

\author{
Yiying Hao ${ }^{\mathrm{a}, \mathrm{b}}$, Jian Kang ${ }^{\mathrm{a} *}$ \\ ${ }^{a}$ School of Architecture, University of Sheffield, Western Bank, Sheffield S10 2TN, United Kingdom \\ ${ }^{b}$ INCAS $^{3}$, Assen, Dr. Nassaulaan 9, 9401 HJ Assen, The Netherlands \\ * Corresponding author
}

\begin{abstract}
The influence of urban morphology of low-density built-up areas on spatial noise level attenuation of flyover aircrafts is investigated at a mesoscale. Six urban morphological parameters, including Building Plan Area Fraction, Complete Aspect Ratio, Building Surface Area to Plan Area Ratio, Building Frontal Area Index, Height-to-Width Ratio, and Horizontal Distance of First-row Building to Flight Path, have been selected and developed. Effects of flight altitude and horizontal flight path distance to site, on spatial aircraft noise attenuation, are examined, considering open areas and façades. Twenty sampled sites, each of $250 \mathrm{~m} * 250 \mathrm{~m}$, are considered. The results show that within $1000 \mathrm{~m}$ horizontal distance of flight path to a site, urban morphology plays an important role in open areas, especially for the buildings with high sound absorption façades, where the variance of average noise level attenuation among different sites is about $4.6 \mathrm{~dB}^{2}$ at $3150 \mathrm{~Hz}$. The effect of flight altitude of $200 \mathrm{ft}-400 \mathrm{ft}$ on average noise level attenuation is not significant, within about $2 \mathrm{~dB}$ at both $630 \mathrm{~Hz}$ and $1600 \mathrm{~Hz}$ in open areas. Urban morphological parameters influence the noise attenuation more in open areas than that on façades. Spatial noise attenuation of flyover aircrafts is mainly correlated to Building Frontal Area Index and Horizontal Distance of First-row Building to Flight Path.
\end{abstract}

Key words: aircraft noise; urban morphology; noise attenuation; low-density area; flight altitude

2014 Applied Acoustics

Date Received: 2 May 2013 Date Accepted: 4 December 2013

Publish online: 21 January 2014

\section{Introduction}

The concerns on the impacts of air transport on noise, air quality, water quality and the ecology are increasing, especially for the higher density population European regions [1]. The annoyance of the population who had been living near a big European airport for at least 5 years caused by aircraft noise has been raised over recent years and the annoyance ratings due to aircraft noise were higher than predicted by the EU standard curves [2]. Aircraft noise has been an important cause for the degradation of soundscape in the adjacent areas of airports, especially for the regions that have strong connections between noise annoyance and local outdoor life [3,4].

Conventionally, the research on aircraft noise mapping and assessment is based on the standard conditions of constant flight speed and flat terrain without reflecting objects [5]. At present, much attention is still paid to large-scale aircraft noise modelling [6,7] and mapping with an emphasis on aircraft flight performance, rather than the effects of built-up obstacles on noise attenuation [8-10]. While many prediction tools mainly focus on the noise from taking offs and landings, noise mapping tools for aircraft taxing have also been developed [11]. On the other hand, with the expansion of air transport and injection of airports and heli-pads into or close to city areas, the effects of morphology of urbanised areas, for instance, the effects of urban street pattern [12,13], have become a concern on aircraft noise distribution near airports. It is indicated through modelling that noise from an aircraft passing overhead in a city street is enhanced compared to that heard in an open area [14]. Kinney et al [13] carried out a series of field experiments which confirmed the enhancement and explained the 
phenomenon. It has been demonstrated that relative Effective Perceived Noise Level increases with the ratio of building height to flying altitude, but the street width has little influence [12]. While the above research demonstrated the importance of considering the influence of urban morphology, there are further important research questions: are there any other parameters of urban morphology which influence aircraft noise attenuation, considering the mesoscale of urban morphology with a group of buildings, rather than a street?

The aim of this study is therefore to explore whether and how urban morphology parameters influences noise attenuation of flyover aircrafts. Low-density residential areas are considered, because they have relatively low noise resistance and they are more common near airports. The study focuses on flyover landing aircrafts or helicopters, of which the noise is prone to be loud, lasting and annoying [12, 15-18]. In particular, this study aims to find out (1) the effects of horizontal distance between a site and flight path; (2) the effects of altitude of flight path. Given the needs for quiet rooms for people to relax, sleep and restore and an impact of quiet side on the aircraft noise annoyance ratings [2], besides open areas, the noise attenuation on façades is also considered.

\section{Methods}

\subsection{Site selection}

To select study sites with diverse urban morphologies from low-density residential areas, Assen in the Netherlands was considered which has a long history of province capital since 1258. It is the fastestgrowing city in the North of Netherlands and has an increase of 5,000 residential buildings per 10 years since 1960 [19], resulting in a mixture of various urban morphologies generated in different historical periods, representing typical European sub-urban morphologies which can often be found near airports. According to a GIS database of 763 grids of Assen built-up areas, less than $10 \%$ grids are used for industry and commercial purposes, and the main function of the built-up areas is residence and mixeduse (residential and commercial). More than $70 \%$ of the residential buildings are low-rise terraced and detached buildings [19]. Twenty sites, each of $250 \mathrm{~m} * 250 \mathrm{~m}$, were sampled by using Simple Random Sample (SRS) method from the GIS database. Figure 1 shows the figure-ground diagrams of the sampled sites.

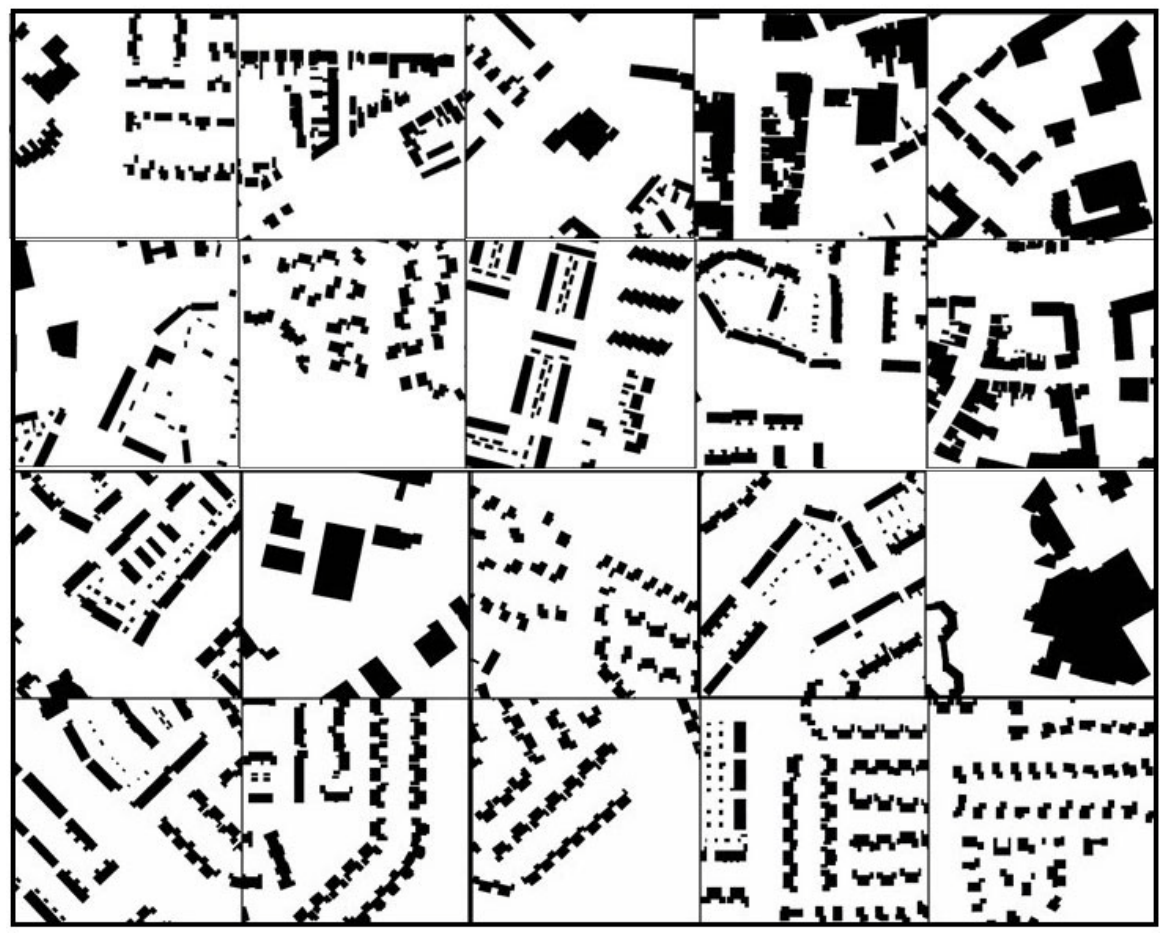

Fig. 1. Figure-ground diagrams of the 20 sampled sites, each of $250 \mathrm{~m} * 250 \mathrm{~m}$, where buildings are in black, and open areas are in white. 


\subsection{Set-up of calculation parameters for noise mapping}

Noise mapping techniques [20-22] were employed with the software package of Cadna/A [23] in this study. The accuracy in noise mapping calculation depends more on the quality of input data rather than specific modelling program [24]. It has been stated that the results of calculation and measurement can generally reach a rather good agreement [24, 25, 26]. For instance, when considering both traffic noise and fountain sounds in urban areas, the inaccuracy is within around 2dB [25]. The 2D polygon maps of the sampled sites were obtained from the web of Zoning Plan [27] and TOP10NL of Kadaster [28], which include the 3D information of buildings. As the aim of this study is to examine the influence of urban morphology, the atmospheric effect is not taken into account, and generic source conditions were considered. The flyover aircraft was set as a line source, considering five horizontal distances from a given site, namely $0 \mathrm{~m}, 100 \mathrm{~m}, 300 \mathrm{~m}, 600 \mathrm{~m}$ and $1000 \mathrm{~m}$, and two flight altitudes, namely $60.96 \mathrm{~m}$ (200ft) and $121.92 \mathrm{~m}(400 \mathrm{ft})$, according to previous studies [12, 13]. The receiver height was set as $1.6 \mathrm{~m}$. The calculation configuration is shown in Fig. 2. Based on the research by Khardi [29], three main frequencies of aircraft noise, $630 \mathrm{~Hz}$ (low), $1600 \mathrm{~Hz}$ (medium), and $3150 \mathrm{~Hz}$ (high), were selected for calculation. The absorption coefficient was assigned as 0.3 across frequencies, considering the mixture of windows and masonry façades, and the ground absorption was assigned as 0 . The reflection order by buildings was set as 3, based on a previous study [24], and comparison was also made by considering no reflections so that the shielding effects as well as the effectiveness of absorptive building façades like green walls can be examined.

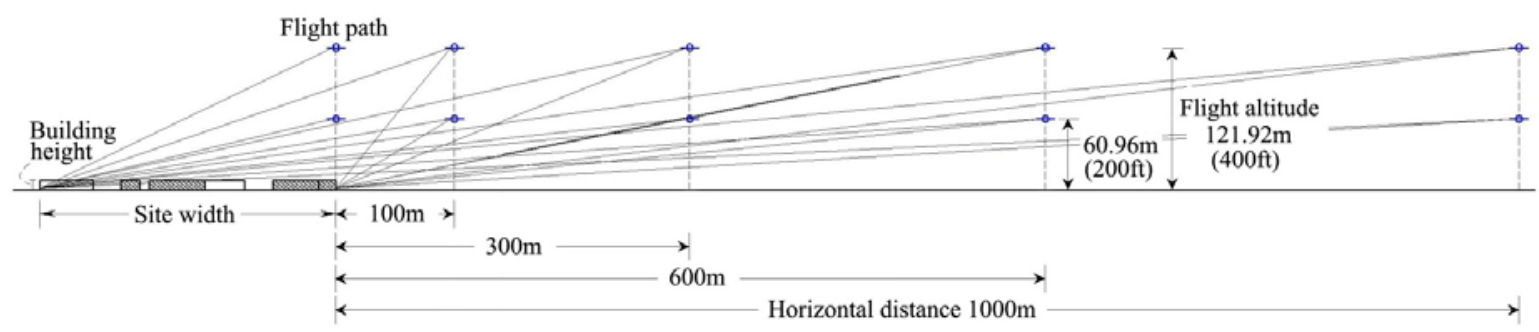

Fig. 2. Cross-section of the calculation configuration, showing the location of flight path.

\subsection{Matlab processing}

To transform the RGB raster noise maps into the matrices of spatial noise level values, a Matlab program has been developed. The program can arrange all the spatial noise level values in a descending order to obtain the indices of spatial $L_{n}$, where for example, $L_{\max }$ represents the highest value in the ranking, $\mathrm{L}_{\min }$ represents the lowest value, and $\mathrm{L}_{10}$ is the top $10 \%$ value [30]. In this study, $\mathrm{L}_{10}, \mathrm{~L}_{90}$ and $\mathrm{L}_{50}$ were chosen to indicate the high, low and middle spatial levels, respectively. In addition, $\mathrm{L}_{\mathrm{avg}}$, the mean of all the spatial noise levels of a given site, was calculated. The sound level values on building façades and in open areas were separately processed.

\subsection{Calculation of urban morphological parameters}

A set of urban morphological parameters have been developed and employed in different domains of environmental studies including environmental performance, atmospheric and wind environment and traffic noise [31-34]. To consider various acoustic effects such as distance, barrier and street canyon, [24,35], in this study six parameters were selected or developed, including Building Plan Area Fraction (BPAF), Complete Aspect Ratio (CAR), Building Surface Area to Plan Area Ratio (BSAPAR), Building Frontal Area Index (BFAI), Height-to-Width Ratio (HWR) and Horizontal Distance of Firstrow Building to Flight Path (HDFBFP), as listed in Table 1, where the first three parameters are independent from the source condition, whereas the other three are related to sound source locations. In this paper, they are grouped as independent and dependent parameters, respectively. Calculations of the 20 sites show that BPAF is evenly distributed from 0.13 to 0.38 , CAR from 1.17 to 1.53 , BSAPAR from 0.36 to 0.88 , BFAI from 0.04 to 0.15 , and HWR from 0.09 to 0.62 . When the horizontal distance between site and flight path is 0, HDFBFP covers a range of $3.4 \mathrm{~m}$ to $116.2 \mathrm{~m}$. 
Table 1. Calculations of the six urban morphological parameters used in this study.

\begin{tabular}{|c|c|c|c|}
\hline Parameter & Definition & Formula & Notes \\
\hline $\begin{array}{l}\text { Building Plan Area } \\
\text { Fraction (BPAF) }\end{array}$ & $\begin{array}{l}\text { The ratio of the plan area of } \\
\text { buildings to the total surface area } \\
\text { of the study region }\end{array}$ & $B P A F=\frac{A_{p}}{A_{T}}$ & $\begin{array}{l}A_{p} \text { is the plan area of buildings } \\
\text { at ground level and } A_{T} \text { is the } \\
\text { total plan area of the region of } \\
\text { interest. }\end{array}$ \\
\hline $\begin{array}{l}\text { Complete Aspect } \\
\text { Ratio }(C A R)\end{array}$ & $\begin{array}{l}\text { The summed area of roughness } \\
\text { elements and exposed ground } \\
\text { divided by the total surface area of } \\
\text { the study region [36] }\end{array}$ & $\begin{array}{l}C A R=\frac{A_{C}}{A_{T}} \\
=\frac{A_{W}+A_{r}+A_{G}}{A_{T}}\end{array}$ & $\begin{array}{l}A_{C} \text { is the combined surface } \\
\text { area of the buildings and } \\
\text { exposed ground, } A_{W} \text { is the wall } \\
\text { surface area, } A_{r} \text { is the roof } \\
\text { area, } A_{G} \text { is the area of exposed } \\
\text { ground [37]. }\end{array}$ \\
\hline $\begin{array}{l}\text { Building Surface } \\
\text { Area to Plan Area } \\
\text { Ratio (BSAPAR) }\end{array}$ & $\begin{array}{l}\text { The sum of building surface area } \\
\text { divided by the total surface area of } \\
\text { the study region }\end{array}$ & $\begin{array}{l}\text { BSAPAR } \\
=\frac{A_{r}+A_{W}}{A_{T}}\end{array}$ & $\begin{array}{l}A_{r} \text { is the plan area of rooftops, } \\
A_{W} \text { is the total area of non- } \\
\text { horizontal roughness element } \\
\text { surfaces (e.g. walls) [37]. }\end{array}$ \\
\hline $\begin{array}{l}\text { Building Frontal } \\
\text { Area Index (BFAI) }\end{array}$ & $\begin{array}{l}\text { The total area of the façade areas } \\
\text { parallel with the flight direction } \\
\left(A_{\text {para }}\right) \text { divided by the total surface } \\
\text { area of the study region }\end{array}$ & $\operatorname{BFAI}(\theta)=\frac{A_{\text {para }}}{A_{T}}$ & $\theta$ is the flight path direction. \\
\hline $\begin{array}{l}\text { Height-to-Width } \\
\text { Ratio (HWR) }\end{array}$ & $\begin{array}{l}\text { The average of the building } \\
\text { heights }\left(H_{a v g}\right) \text { is divided by the } \\
\text { average of the horizontal distances } \\
\text { between two adjacent buildings on } \\
\text { the direction vertical to the flight } \\
\text { direction }\left(\mathrm{S}_{a v g}\right)\end{array}$ & $H W R(\theta)=\frac{H_{a v g}}{S_{a v g}}$ & $\theta$ is the flight path direction. \\
\hline $\begin{array}{l}\text { Horizontal } \\
\text { Distance of First- } \\
\text { row Building to } \\
\text { Flight Path } \\
(\text { HDFBFP) }\end{array}$ & $\begin{array}{l}\text { The mean of the horizontal } \\
\text { distances from the frontal façades } \\
\text { of the first-row buildings to the } \\
\text { flight path }\end{array}$ & $D F B R=\frac{1}{n} \sum_{i=1}^{n} d_{i}$ & $\begin{array}{l}n \text { is the total number of first- } \\
\text { row buildings, and } d_{i} \text { is the } \\
\text { distance from the first-row } \\
\text { building to the flight path. }\end{array}$ \\
\hline
\end{tabular}

\section{Results}

\subsection{Effects of the horizontal distance between site and flight path}

Figure 3 shows the maximum, minimum, and mean aircraft noise attenuation (re. source power level) among the 20 sampled sites, in terms of $\mathrm{L}_{\text {avg }}$ at 630,1600 and $3150 \mathrm{~Hz}$, with a range of horizontal distance between site and flight path, when the flight altitude is 200ft. In the figure the noise attenuation of each site is also shown. It can be seen that the difference between the maximum and minimum values among the 20 sites in open areas generally increases with horizontal distance between site and flight path, and reaches $7.9 \mathrm{~dB}$ at $1000 \mathrm{~m}$, at $3150 \mathrm{~Hz}$ (see Fig. 1-c). It is also interesting to note that from $300 \mathrm{~m}$ to $600 \mathrm{~m}$, namely when the horizontal distance between site and flight path is doubled, the mean $\mathrm{L}_{\text {avg }}$ difference among the 20 sites in open areas reduces by $6.9 \mathrm{~dB}$ at $630 \mathrm{~Hz}, 7.5 \mathrm{~dB}$ at $1600 \mathrm{~Hz}$, and $16.1 \mathrm{~dB}$ at $3150 \mathrm{~Hz}$, as shown in Fig. 3a, $3 \mathrm{~b}$ and 3c, respectively, demonstrating the significant influence of urban morphology.

In general, the sound level variations among the 20 sites are larger in open areas than those on façades. For example, by comparing Fig. $3 \mathrm{~b}$ and $3 e$, it can be seen that at $1600 \mathrm{~Hz}$ at $1000 \mathrm{~m}$, the difference between the maximum and minimum values is $7.7 \mathrm{~dB}$ in open areas and $4.5 \mathrm{~dB}$ on façades. However, the façades have higher noise attenuation than that in open areas, in terms of the mean $\mathrm{L}_{\text {avg }}$ of the 20 sites. 
For example, by comparing Fig. 3a and 3d, it can be seen that at $630 \mathrm{~Hz}$ at $1000 \mathrm{~m}$, the value is $54.0 \mathrm{~dB}$ on façades and $49.2 \mathrm{~dB}$ in open areas.

Fig. 4 and 5 show the variances of the aircraft noise attenuation $L_{a v g}$ among the 20 sites, in open areas and on façades, respectively. It can be seen in Fig. 4 that generally speaking, with the increase of distance, the variances at all the frequencies go up. Corresponding to Fig. 3, the variances at $1000 \mathrm{~m}$ are the largest, where at $3150 \mathrm{~Hz}$ and altitude of $200 \mathrm{ft}$ the variance is $4.6 \mathrm{~dB}^{2}$, higher than that at $1600 \mathrm{~Hz}$ and $630 \mathrm{~Hz}$ (see Fig. 4a, 4b and 4c). By comparing Figs. 4 and 5, it can be seen that the variances of noise attenuation on façades, mostly below $2 \mathrm{~dB}^{2}$, are lower than those in open areas.

In Fig. 4 and 5 two conditions, with a reflection order of 0 and 3, are considered. Compared with the condition without reflections, the variances with 3 reflections are lower at almost all the distances, which means that sound reflections by buildings reduce the influence of morphology on the noise resistance. At a large horizontal distance between site and flight path, say $1000 \mathrm{~m}$, the differences in variances between reflection order of 0 and 3 can be neglected, in open areas and also on façades.

The variances in terms of $\mathrm{L}_{10}, \mathrm{~L}_{50}$ and $\mathrm{L}_{90}$ are shown in Table 2. It can be seen that the variances of $\mathrm{L}_{50}$ and $\mathrm{L}_{90}$ are generally higher than those of $\mathrm{L}_{10}$, and the variances in open areas are higher than those on façades, suggesting that urban morphology may have more influence on the noise attenuation at the middle level and the quiet level in open areas. The highest variance occurs for $\mathrm{L}_{50}$ at $1600 \mathrm{~Hz}$ at $1000 \mathrm{~m}$, which is $19.7 \mathrm{~dB}^{2}$.

Table 2. Variances of the aircraft noise attenuation among the 20 sites in terms of $\mathrm{L}_{10}, \mathrm{~L}_{50}$ and $\mathrm{L}_{90}$, both in open areas and on façades.

\begin{tabular}{|c|c|c|c|c|c|c|c|c|c|c|}
\hline \multirow{2}{*}{\multicolumn{2}{|c|}{ Frequency(Hz) }} & \multicolumn{3}{|c|}{$\mathbf{L}_{10}$} & \multicolumn{3}{|c|}{$\mathbf{L}_{50}$} & \multicolumn{3}{|c|}{$\mathbf{L}_{90}$} \\
\hline & & 630 & 1600 & 3150 & 630 & 1600 & 3150 & 630 & 1600 & 3150 \\
\hline \multirow{6}{*}{$\begin{array}{c}\text { Open } \\
\text { Areas }\end{array}$} & Distance(m) & & & & & & & & & \\
\hline & 0 & 1.4 & 2.6 & 0.0 & 0.6 & 1.2 & 3.8 & 1.8 & 1.0 & 5.7 \\
\hline & 100 & 0.8 & 1.4 & 2.0 & 4.6 & 5.2 & 8.1 & 0.0 & 3.4 & 1.2 \\
\hline & 300 & 3.0 & 0.5 & 3.0 & 3.6 & 7.6 & 3.8 & 2.2 & 0.9 & 3.3 \\
\hline & 600 & 6.8 & 2.1 & 5.8 & 2.1 & 5.3 & 1.6 & 1.0 & 1.6 & 2.2 \\
\hline & 1000 & 0.0 & 0.8 & 1.2 & 8.6 & 19.7 & 8.9 & 1.8 & 6.2 & 3.2 \\
\hline \multirow[t]{5}{*}{ Façades } & 0 & 0.4 & 0.9 & 0.4 & 0.2 & 0.8 & 1.2 & 1.7 & 6.0 & 6.4 \\
\hline & 100 & 1.2 & 0.5 & 1.0 & 0.6 & 1.0 & 0.6 & 7.4 & 9.0 & 4.2 \\
\hline & 300 & 1.0 & 0.4 & 0.8 & 4.6 & 0.8 & 1.0 & 5.0 & 3.3 & 3.6 \\
\hline & 600 & 3.3 & 0.4 & 0.4 & 1.0 & 1.6 & 2.0 & 2.2 & 6.1 & 8.5 \\
\hline & 1000 & 1.0 & 1.6 & 2.4 & 1.0 & 1.2 & 4.6 & 3.7 & 0.9 & 0.8 \\
\hline
\end{tabular}




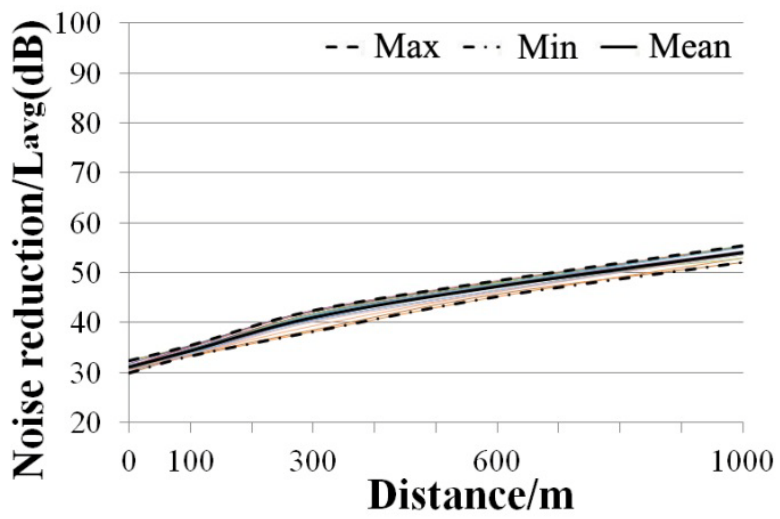

(a) $630 \mathrm{~Hz}$, open areas

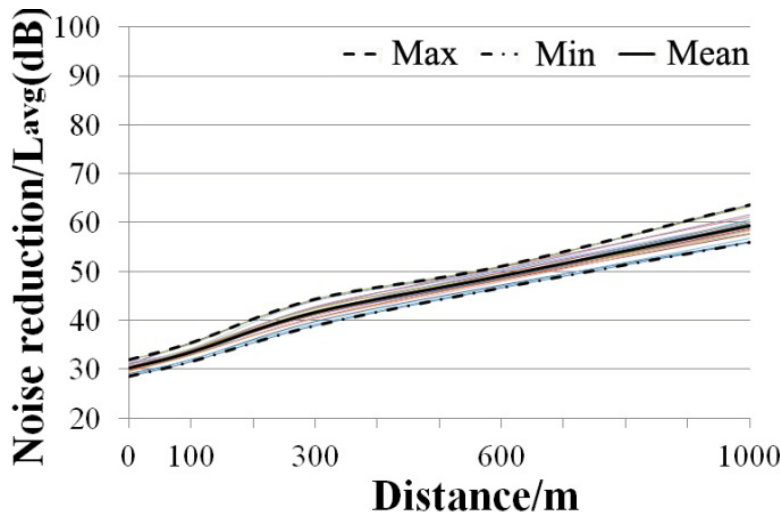

(b) $1600 \mathrm{~Hz}$, open areas

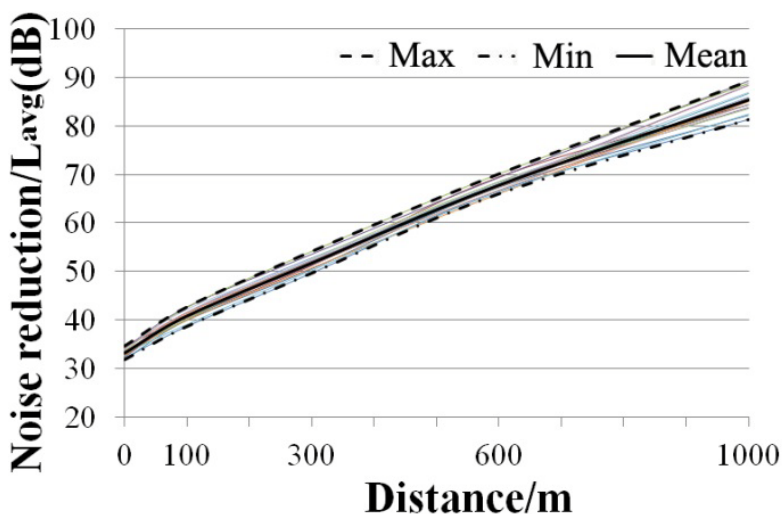

(c) $3150 \mathrm{~Hz}$, open areas

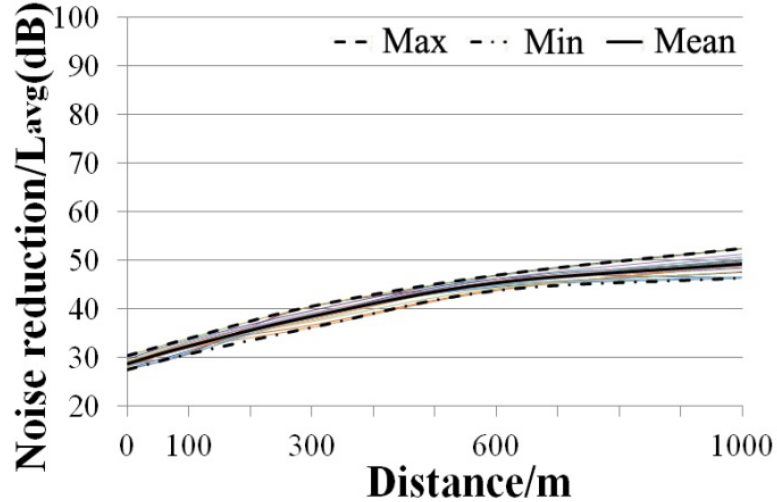

(d) $630 \mathrm{~Hz}$, façades

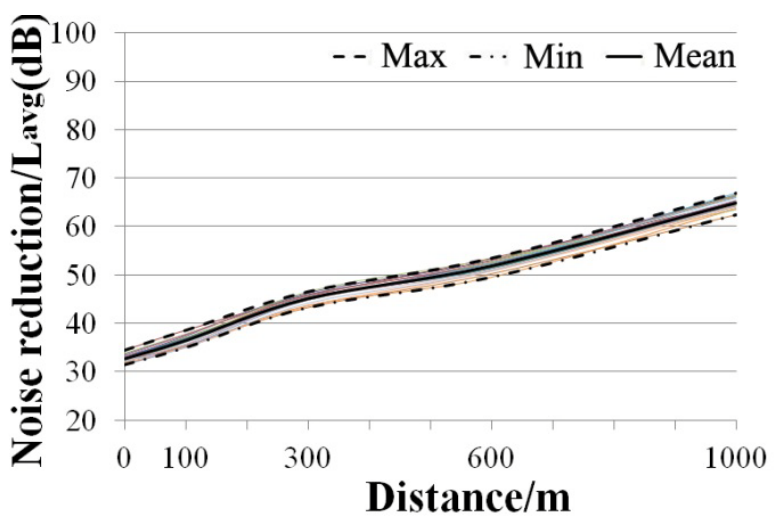

(e) $1600 \mathrm{~Hz}$, façades

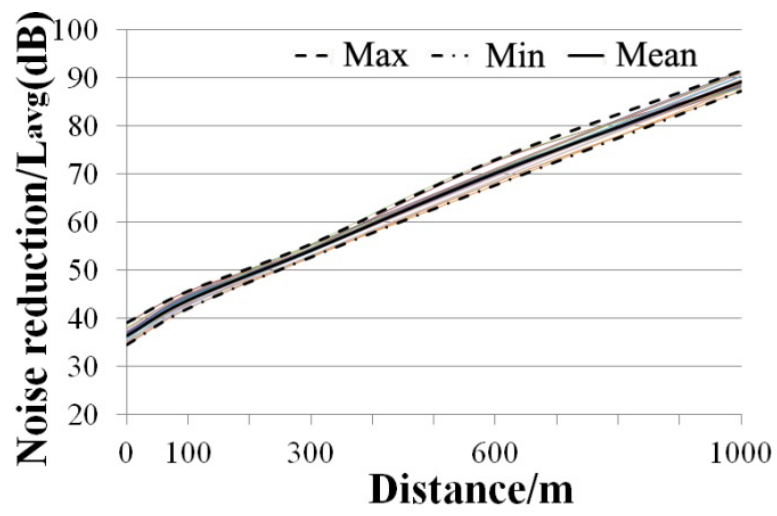

(f) $3150 \mathrm{~Hz}$, façades

Fig. 3. The maximum, minimum, and mean aircraft noise attenuation (re. source power level) among the 20 sampled sites, in terms of $\mathrm{L}_{\text {avg }}$ at 630,1600 and $3150 \mathrm{~Hz}$, with horizontal distances between site and flight path of $0 \mathrm{~m}, 100 \mathrm{~m}, 300 \mathrm{~m}, 600 \mathrm{~m}$ and $1000 \mathrm{~m}$, where the flight altitude is $200 \mathrm{ft}$. In the figure the noise attenuation of each site is also shown, although individual sites are not identified. 


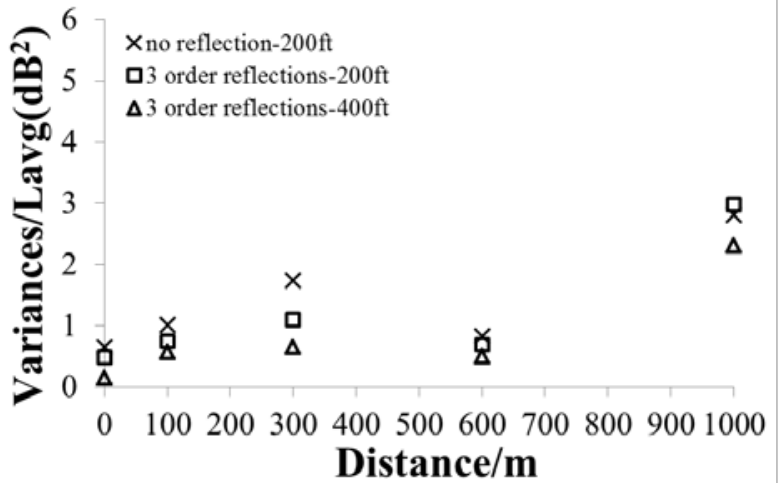

(a) $630 \mathrm{~Hz}$

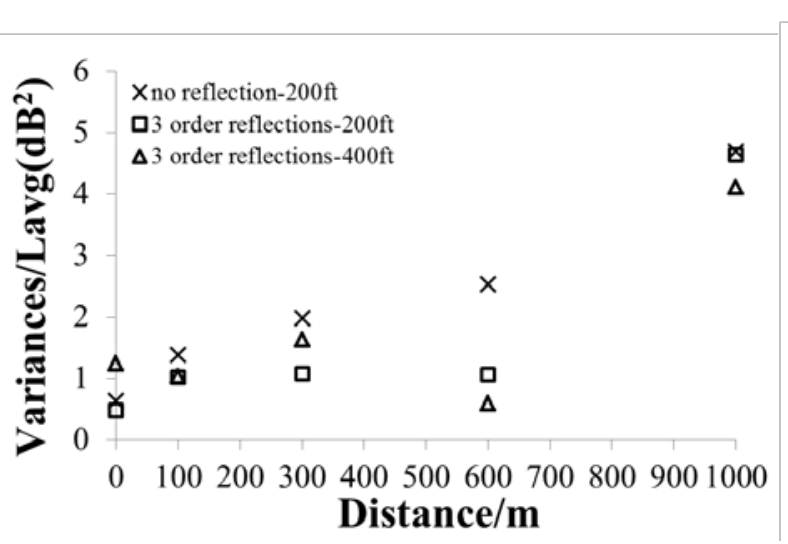

(c) $3150 \mathrm{~Hz}$

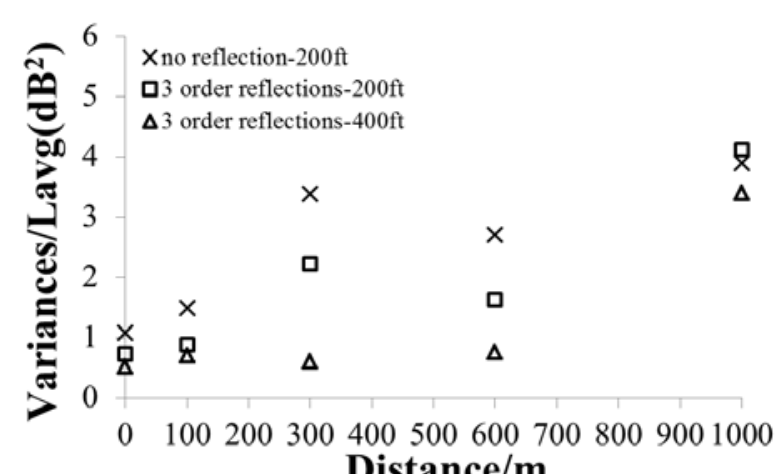

Distance/m

(b) $1600 \mathrm{~Hz}$
Fig. 4. Variances of the aircraft noise attenuation $\mathrm{L}_{\mathrm{avg}}$ in open areas among the 20 sites, with increasing horizontal distance between site and flight path of $0 \mathrm{~m}, 100 \mathrm{~m}, 300 \mathrm{~m}, 600 \mathrm{~m}$ and $1000 \mathrm{~m}$.

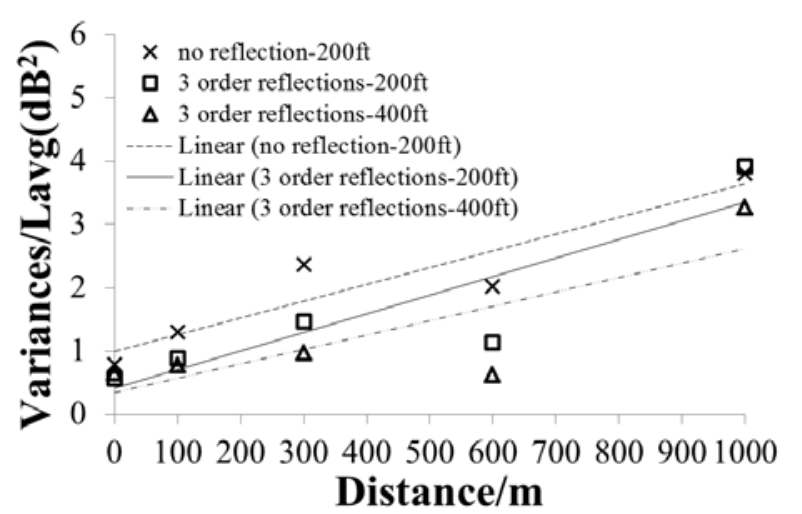

(d) Average of 3 frequencies

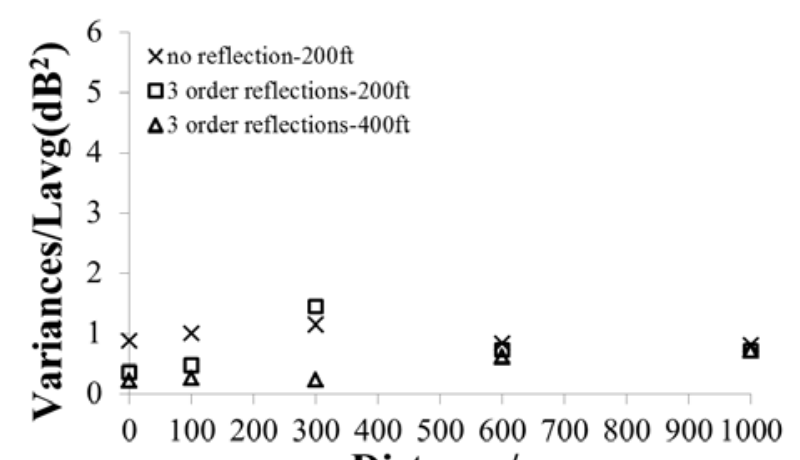

Distance/m

(a) $630 \mathrm{~Hz}$

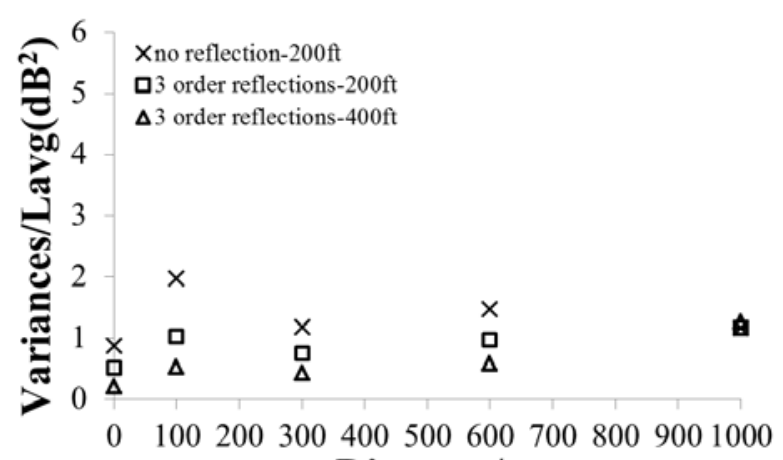

Distance/m

(b) $1600 \mathrm{~Hz}$ 


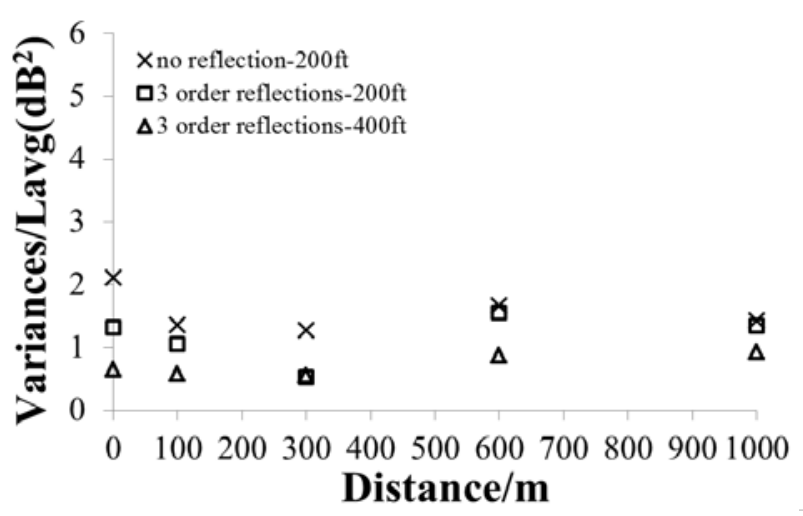

(c) $3150 \mathrm{~Hz}$

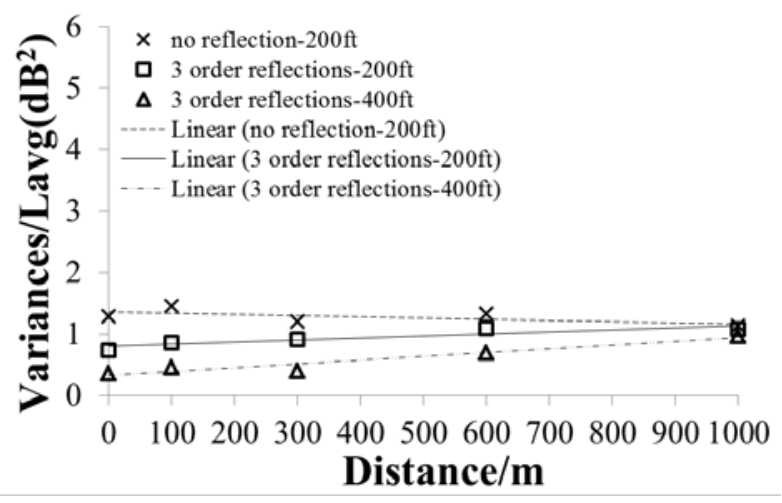

(d) Average of 3 frequencies

Fig. 5. Variances of the aircraft noise attenuation $L_{\text {avg }}$ on façades among the 20 sites, with increasing horizontal distance between site and flight path of $0 \mathrm{~m}, 100 \mathrm{~m}, 300 \mathrm{~m}, 600 \mathrm{~m}$ and $1000 \mathrm{~m}$.

\subsection{Effects of flight altitude}

Fig. 6 compares the mean values of aircraft noise attenuation (re. source power level) of the 20 sites between the flight altitude of $200 \mathrm{ft}$ and $400 \mathrm{ft}$, in terms of $\mathrm{L}_{\text {avg }}, \mathrm{L}_{10}$ and $\mathrm{L}_{90}$. It is interesting to note that the increase to $400 \mathrm{ft}$ from $200 \mathrm{ft}$ in flight altitude generally does not benefit the noise attenuation. This is perhaps because although the increase in flight altitude results in larger source-receiver distances, it also decreases the shielding effects of buildings. It was shown in a previous study that the enhancement of sound level by streets relative to that in the open field decreases with the increase of flight altitude, from $5.0 \mathrm{dBA}$ at $200 \mathrm{ft}$ to $2.0 \mathrm{dBA}$ at $400 \mathrm{ft}$ [13]. In Fig. 6 it can be seen that at $1000 \mathrm{~m}$, there is almost no difference in noise attenuation between the two altitudes.

In Figs. 4 and 5 comparisons of variances of spatial noise attenuation between the two flight altitudes are also shown. It can be seen that the increase of altitude does not significantly diminish the variances. In other words, the effect in the change of altitude on the influence of urban morphology on noise resistance is rather small, less than $1 \mathrm{~dB}$ mostly.

Compared with façades, the influence of altitude on noise attenuation in open areas is more significant in terms of $\mathrm{L}_{90}$, as can be seen by comparing Figs. 6c and 6f, but surprisingly, the noise attenuation is generally higher at the altitude of $200 \mathrm{ft}$ than $400 \mathrm{ft}$, which means that in certain situations, the increase of altitude does not decrease, but increase the sound levels in relatively quiet areas, of which the reason might be that the shielding effect that plays a key role in quiet area protection decreases with the increase of flight altitude.

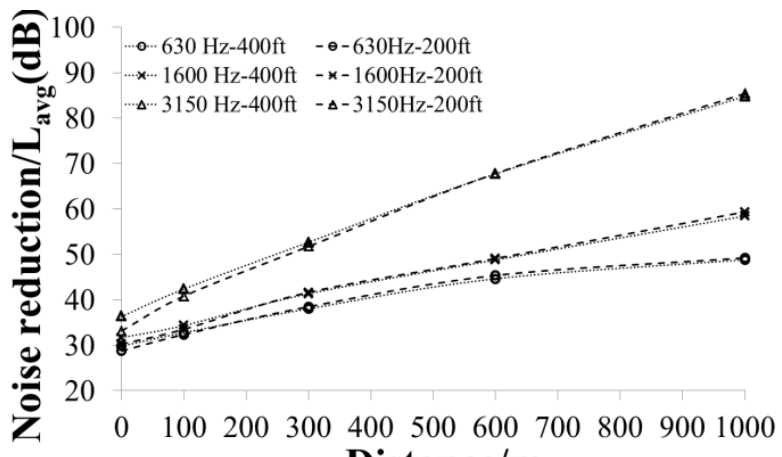

Distance/m

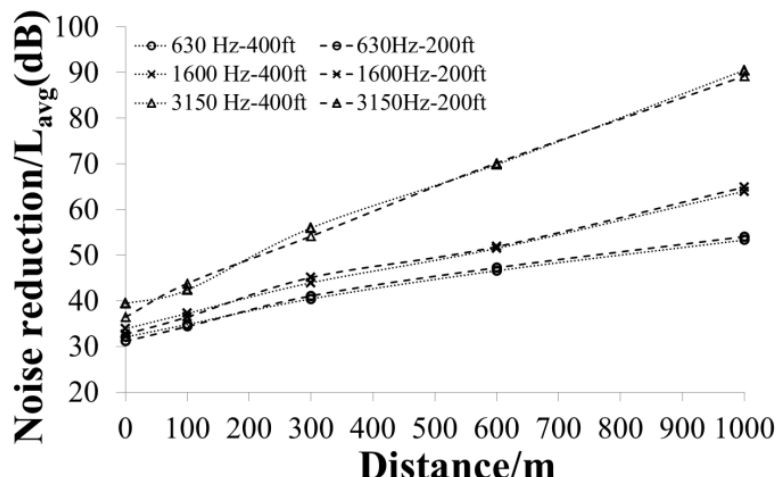

(d) $\mathrm{L}_{\text {avg }}$ on façades

(a) $\mathrm{L}_{\text {avg }}$ in open areas 


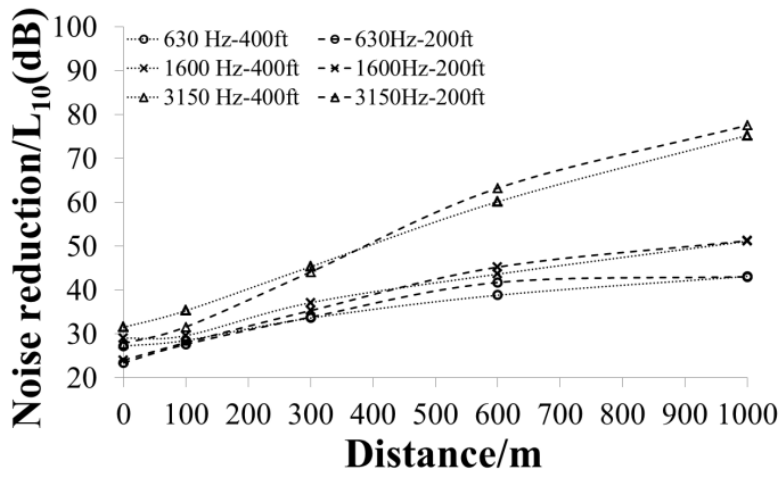

(b) $\mathrm{L}_{10}$ in open areas

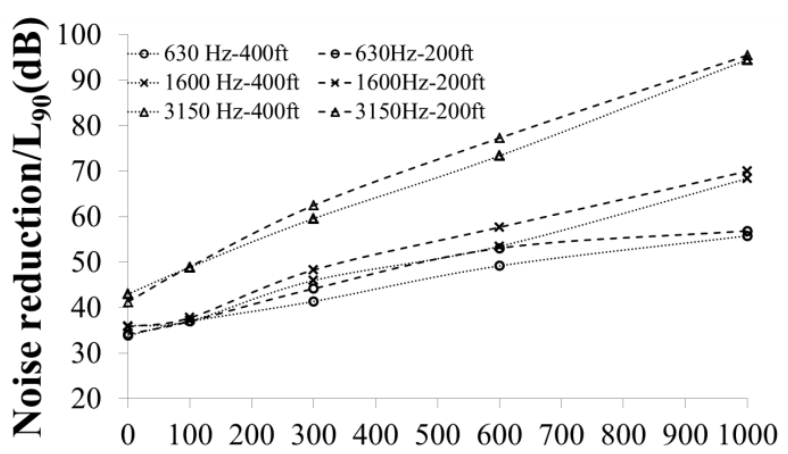

Distance/m

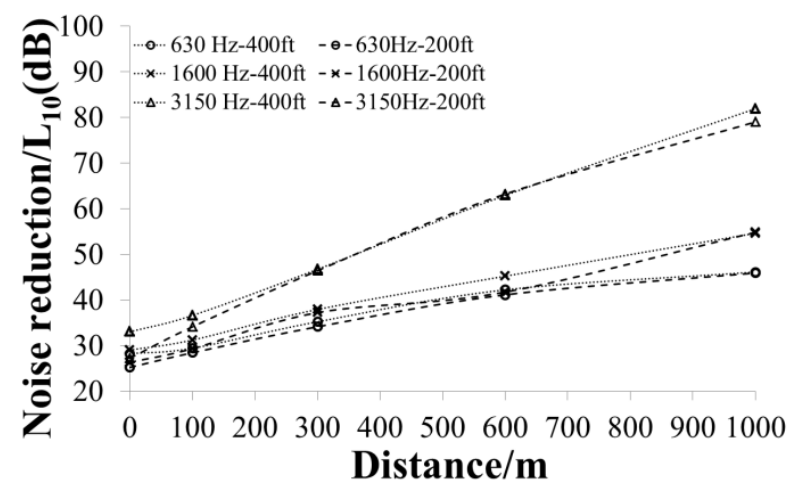

(e) $\mathrm{L}_{10}$ on façades

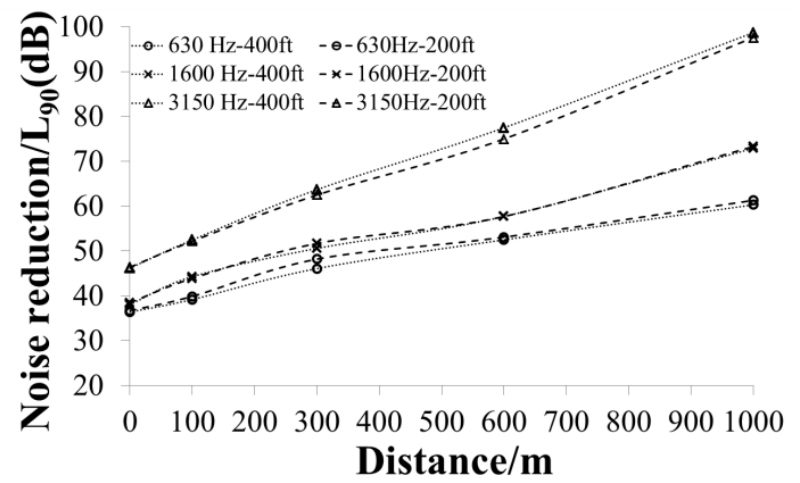

(f) $\mathrm{L}_{90}$ on façades

Fig. 6. The mean values of aircraft noise attenuation (re. source power level) of the 20 sites between the flight altitude of $200 \mathrm{ft}$ and $400 \mathrm{ft}$, in terms of $\mathrm{L}_{\mathrm{avg}}, \mathrm{L}_{10}$ and $\mathrm{L}_{90}$, with increasing horizontal distance between site and flight path of $0 \mathrm{~m}, 100 \mathrm{~m}, 300 \mathrm{~m}, 600 \mathrm{~m}$ and $1000 \mathrm{~m}$.

3.3 The relations between aircraft noise attenuation and independent urban morphological parameters

Relationships between aircraft noise attenuation and independent morphological parameters have been examined with the flight altitude of 200ft, since the variances are higher than those of $400 \mathrm{ft}$. Three typical horizontal distances between site and flight path are considered, which are $0 \mathrm{~m}, 300 \mathrm{~m}$, and $1000 \mathrm{~m}$.

Among the three independent urban morphological parameters, namely Building Plan Area Fraction (BPAF), Complete Aspect Ratio (CAR), and Building Surface Area to Plan Area Ratio (BSAPAR), at the distances of $0 \mathrm{~m}, 300 \mathrm{~m}$ and $1000 \mathrm{~m}, \mathrm{BPAF}$ is not significantly correlated to any of the acoustic

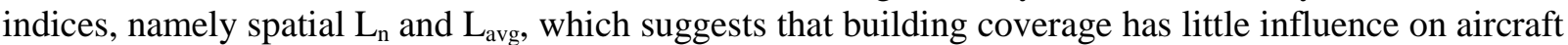
noise resistance, while CAR and BSAPAR have more significant correlations $(p<0.05)$ with the indices, as shown in Tables 3 and 4, respectively.

It can be seen in Table 3 that CAR is more correlated to the indices in open areas, mostly in terms of $\mathrm{L}_{90}$, which means that the total surface area of building and ground may significantly influence the noise level in quiet areas. Fig. 7 further illustrates the tendencies of $\mathrm{L}_{90}$ at $630 \mathrm{~Hz}\left(\mathrm{R}^{2}=0.567\right)$ and $3150 \mathrm{~Hz}$ $\left(\mathrm{R}^{2}=0.586\right)$ with a change of CAR, as examples. When CAR increases the regression line of either $\mathrm{L}_{90}$ of $630 \mathrm{~Hz}$ or $3150 \mathrm{~Hz}$ in open areas goes up and then becomes stable after CAR is higher than approximately 1.4. In other words, the importance of CAR on noise attenuation in open areas becomes less when CAR is higher than 1.4. The correlations also exist between CAR and the acoustic indices on façades, but they are not at a significant level statistically. 
From Table 4 it can be seen that BSAPAR also tends to have high correlations with the acoustic indices, especially $\mathrm{L}_{90}$ in open areas. The tendencies of $\mathrm{L}_{90}$ in open areas at $630 \mathrm{~Hz}\left(\mathrm{R}^{2}=0.592\right)$ and $3150 \mathrm{~Hz}$ $\left(\mathrm{R}^{2}=0.500\right)$ with a change of BSAPAR are further illustrated in Fig. 8. It can be seen in Fig. 8 that the noise attenuation in open areas at $\mathrm{L}_{90}$ increases before BSAPAR is about 0.7 and then decreases, both at $630 \mathrm{~Hz}$ and $3150 \mathrm{~Hz}$, of which the reason might be that the increase of building surface area induces more sound reflections between buildings, so that further increases noise levels.

Table 3. Significances of the correlations between acoustic indices and Complete Aspect Ratio in terms of $p$ values, where $*$ indicates $p<0.05$ level (2-tailed), and $* *$ indicates $p<0.01$ level (2-tailed) in Bivariate Correlation.

\begin{tabular}{|c|c|c|c|c|c|c|c|c|c|c|}
\hline \multirow{2}{*}{\multicolumn{2}{|c|}{$\begin{array}{c}\text { Distance(m) } \\
\text { Frequency(Hz) }\end{array}$}} & \multicolumn{3}{|c|}{0} & \multicolumn{3}{|c|}{300} & \multicolumn{3}{|c|}{1000} \\
\hline & & 630 & 1600 & 3150 & 630 & 1600 & 3150 & 630 & 1600 & 3150 \\
\hline \multirow{4}{*}{$\begin{array}{l}\text { Open } \\
\text { Areas }\end{array}$} & $\mathrm{L}_{10}$ & .721 & .084 & - & 0.59 & .148 & .805 & - & .449 & .377 \\
\hline & $\mathrm{L}_{50}$ & .402 & .371 & .917 & .272 & .614 & 199 & .363 & .627 & .180 \\
\hline & $\mathrm{L}_{90}$ & $.005 * *$ & 151 & $.001 * *$ & .082 & .170 & .477 & $.008 * *$ & $.005 * *$ & $.037 *$ \\
\hline & $\mathrm{L}_{\mathrm{avg}}$ & .070 & .060 & .536 & $.036 *$ & .169 & .261 & .100 & .130 & .222 \\
\hline \multirow[t]{4}{*}{ Façades } & $\mathrm{L}_{10}$ & .712 & .121 & .712 & .072 & .712 & .072 & .250 & .060 & .919 \\
\hline & $\mathrm{L}_{50}$ & .325 & .757 & .499 & .061 & .523 & .061 & $.040 *$ & .081 & .147 \\
\hline & $\mathrm{L}_{90}$ & .681 & .779 & .800 & .741 & .820 & .741 & .429 & $.029 *$ & .597 \\
\hline & $L_{\text {avg }}$ & .150 & .553 & .565 & .284 & .806 & .284 & $.044 *$ & .067 & .168 \\
\hline
\end{tabular}

Table 4. Significances of the correlations between acoustic indices and Building Surface Area to Plan Area Ratio in terms of $p$ values, where * indicates $p<0.05$ level (2-tailed), and $* *$ indicates $p<0.01$ level (2-tailed) in Bivariate Correlation.

\begin{tabular}{|c|c|c|c|c|c|c|c|c|c|c|}
\hline \multirow{2}{*}{\multicolumn{2}{|c|}{$\begin{array}{c}\text { Distance(m) } \\
\text { Frequency(Hz) }\end{array}$}} & \multicolumn{3}{|c|}{ 0 } & \multicolumn{3}{|c|}{300} & \multicolumn{3}{|c|}{1000} \\
\hline & & 630 & 1600 & 3150 & 630 & 1600 & 3150 & 630 & 1600 & 3150 \\
\hline \multirow{4}{*}{$\begin{array}{l}\text { Open } \\
\text { Areas }\end{array}$} & $\mathrm{L}_{10}$ & .379 & .140 & - & $.019 *$ & .143 & .264 & - & .373 & .499 \\
\hline & $\mathrm{L}_{50}$ & .466 & .470 & .810 & .453 & .192 & .322 & .150 & .520 & .083 \\
\hline & $\mathrm{L}_{90}$ & $.021 *$ & .297 & $.022 *$ & .173 & .158 & .966 & $.027^{*}$ & $.018^{*}$ & .088 \\
\hline & $\mathrm{L}_{\mathrm{avg}}$ & $.050 *$ & .064 & .883 & .151 & .101 & .157 & .064 & .089 & .264 \\
\hline \multirow[t]{4}{*}{ Façades } & $\mathrm{L}_{10}$ & .379 & .108 & .379 & .051 & .379 & .051 & .512 & $.050 *$ & .773 \\
\hline & $\mathrm{L}_{50}$ & .177 & .854 & .578 & .115 & .584 & .155 & $.039 *$ & .106 & .352 \\
\hline & $\mathrm{L}_{90}$ & .665 & .695 & .941 & .691 & .916 & .691 & .239 & $.010 * *$ & .735 \\
\hline & $\mathrm{L}_{\text {avg }}$ & .260 & .718 & .758 & .315 & .504 & .315 & .071 & .097 & .319 \\
\hline
\end{tabular}




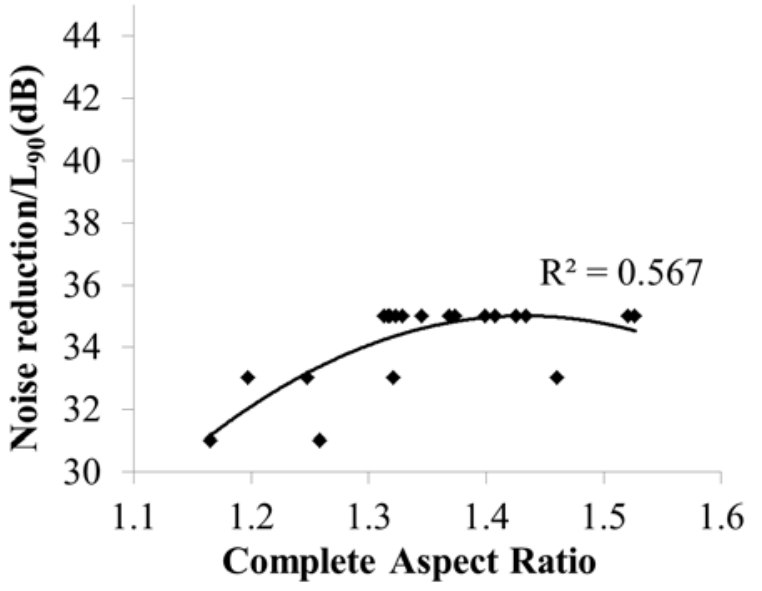

(a) $630 \mathrm{~Hz}$

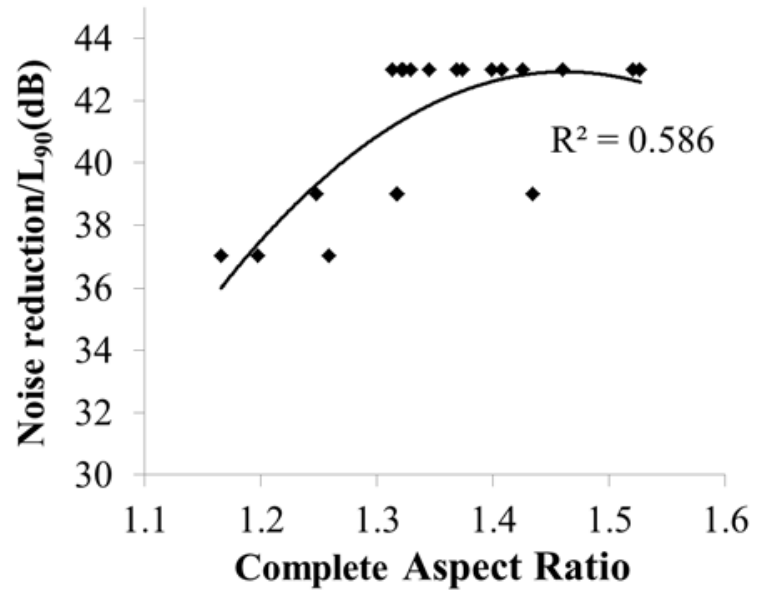

(b) $3150 \mathrm{~Hz}$

Fig. 7. Relationships between $\mathrm{L}_{90}$ in open areas and the Complete Aspect Ratio.

3.4 The relations between aircraft noise attenuation and sound source dependent urban morphological parameters

Three sound source dependent parameters, including Building Frontal Area Index (BFAI), Height-toWidth Ratio (HWR) and Horizontal Distance of First-row Building to Flight Path (HDFBFP), have been also investigated. It has been shown that there is no significant correlation between HWR and the acoustic indices. This corresponds to a study by Ismail and Oldham on the effects of street canyon on noise from low flying aircraft [12], which shows that street width, which is indicated by HWR in the current study, hardly plays a role in the noise attenuation. The correlations between acoustic indices and BFAI and HDFBFP are shown in Tables 5 and 6, respectively. By comparing Tables $3 \& 4$ and 5\&6, it can be seen that generally speaking, the sound source dependent parameters are more correlated to the acoustic indices than the independent ones.

From Table 5 it can be seen that BFAI generally has more correlations with the acoustic indices than the independent parameters when the distance is $1000 \mathrm{~m}$ (see Table 3, 4 and 5), suggesting that for aircraft noise attenuation, the barrier effect of urban morphology may play a more crucial role than the other effects when the distance is relatively large. However, when the horizontal distance between site and flight path becomes smaller, such as $300 \mathrm{~m}$, there is less correlation between acoustic indices and BFAI, since the barrier effects by building façades plays a less significant role.

HDFBFP has the most correlations among the six parameters, especially with the acoustic indices in open areas, as can be seen in Table 6. Unlike CAR, BSAPAR and BFAI, which have fewer correlations in terms of $\mathrm{L}_{\text {avg }}$ and $\mathrm{L}_{50}$ (see Table 3, 4 \&5), HDFBFP is highly correlated to $\mathrm{L}_{\text {avg }}$ (e.g. $p=0.000$, at $1600 \mathrm{~Hz}$ at $0 \mathrm{~m}$ ) and $\mathrm{L}_{50}$ (e.g. $p=0.000$, at $630 \mathrm{~Hz}$ at $1000 \mathrm{~m}$ ) in open areas, although on façades it is almost not correlated with the acoustic indices, as shown in Table 6.

Figure 9 further illustrates the relationships between acoustic indices in open areas and HDFBFP. It can be seen in Fig. 9a that at $0 \mathrm{~m}$, the mean $\mathrm{L}_{\text {avg }}$ at $1600 \mathrm{~Hz}$ decreases slowly with the increase of HDFBFP, which means if a given low-density site has a row of buildings that are close to the flyover aircraft horizontally, the average noise level in open areas might be considerably reduced, due to barrier effect. At $1000 \mathrm{~m}$, the noise attenuations in terms of $\mathrm{L}_{50}$ at $630 \mathrm{~Hz}$ and $3150 \mathrm{~Hz}$ both decrease constantly when HDFBFP increases, and the difference between the maximum and minimum level is rather high, at about 10dB, as can be seen in Fig. 9b and 9c. In other words, the distance between the first row buildings to flight path might play a rather significant role in the protection of quiet open areas in terms of $\mathrm{L}_{\text {avg }}$ and $\mathrm{L}_{50}$. 
Table 5. Significances of the correlations between acoustic indices and Building Frontal Area Index in terms of $p$ values, where * indicates $p<0.05$ level (2-tailed), and $* *$ indicates $p<0.01$ level (2-tailed) in Bivariate Correlation.

\begin{tabular}{|c|c|c|c|c|c|c|c|c|c|c|}
\hline \multirow{2}{*}{\multicolumn{2}{|c|}{$\begin{array}{c}\text { Distance(m) } \\
\text { Frequency(Hz) }\end{array}$}} & \multicolumn{3}{|c|}{ 0 } & \multicolumn{3}{|c|}{300} & \multicolumn{3}{|c|}{1000} \\
\hline & & 630 & 1600 & 3150 & 630 & 1600 & 3150 & 630 & 1600 & 3150 \\
\hline \multirow{4}{*}{$\begin{array}{l}\text { Open } \\
\text { Areas }\end{array}$} & $\mathrm{L}_{10}$ & .640 & $.027^{*}$ & - & .160 & .238 & .583 & - & .390 & .265 \\
\hline & $\mathrm{L}_{50}$ & .258 & .401 & .778 & .544 & .221 & .321 & .065 & .156 & .013 \\
\hline & $\mathrm{L}_{90}$ & .159 & .060 & $.022 *$ & .065 & .239 & .533 & $.002 * *$ & $.002 * *$ & .002* \\
\hline & $\mathrm{L}_{\mathrm{avg}}$ & .149 & $.049 *$ & .323 & .110 & .078 & .328 & $.018 *$ & $.032 *$ & $.029 *$ \\
\hline \multirow[t]{4}{*}{ Façades } & $\mathrm{L}_{10}$ & .640 & $.016 *$ & .640 & .174 & .640 & .174 & .181 & .060 & .421 \\
\hline & $\mathrm{L}_{50}$ & .601 & .842 & .918 & .303 & .158 & .303 & $.002 * *$ & $.020 *$ & .067 \\
\hline & $\mathrm{L}_{90}$ & .839 & .635 & .868 & .913 & .399 & .913 & .662 & .798 & .187 \\
\hline & $\mathrm{L}_{\text {avg }}$ & .244 & .638 & .555 & .551 & .847 & .551 & $.029 *$ & $.033^{*}$ & .064 \\
\hline
\end{tabular}

Table 6. Significances of the correlations between acoustic indices and Horizontal Distance of Building to Flight line in terms of $p$ values, where $*$ indicates $p<0.05$ level (2-tailed), and $* *$ indicates $p<0.01$ level (2-tailed) in Bivariate Correlation.

\begin{tabular}{|c|c|c|c|c|c|c|c|c|c|c|}
\hline \multirow{2}{*}{\multicolumn{2}{|c|}{$\begin{array}{c}\text { Distance(m) } \\
\text { Frequency(Hz) }\end{array}$}} & \multicolumn{3}{|c|}{$\mathbf{0}$} & \multicolumn{3}{|c|}{300} & \multicolumn{3}{|c|}{1000} \\
\hline & & 630 & 1600 & 3150 & 630 & 1600 & 3150 & 630 & 1600 & 3150 \\
\hline \multirow{4}{*}{$\begin{array}{l}\text { Open } \\
\text { Areas }\end{array}$} & $\mathrm{L}_{10}$ & .481 & $.050 *$ & - & .768 & .110 & .147 & - & .909 & .088 \\
\hline & $\mathrm{L}_{50}$ & .194 & .062 & .450 & .650 & $.003^{* *}$ & $.010 * *$ & $.000 * *$ & $.010 * *$ & $.002 * *$ \\
\hline & $\mathrm{L}_{90}$ & .687 & .513 & .355 & .334 & $.032 *$ & .861 & .132 & .091 & $.034 *$ \\
\hline & $\mathrm{L}_{\mathrm{avg}}$ & $.021 *$ & $.000 * *$ & .774 & .712 & $.001 * *$ & $.007 * *$ & $.001 * *$ & $.002^{* *}$ & $.003^{* *}$ \\
\hline \multirow[t]{4}{*}{ Façades } & $\mathrm{L}_{10}$ & .481 & .936. & .481. & $.033^{*}$ & .481 & $.033^{*}$ & .165 & .253 & .309 \\
\hline & $\mathrm{L}_{50}$ & .570 & .360 & .297 & .991 & .194 & .991 & .330 & .401 & .728 \\
\hline & $\mathrm{L}_{90}$ & .657 & .643 & .661 & .994 & .844 & .994 & .337 & .833 & .750 \\
\hline & $\mathrm{L}_{\mathrm{avg}}$ & .530. & .202 & .321 & .894 & .797 & .894 & .922 & .830 & .583 \\
\hline
\end{tabular}




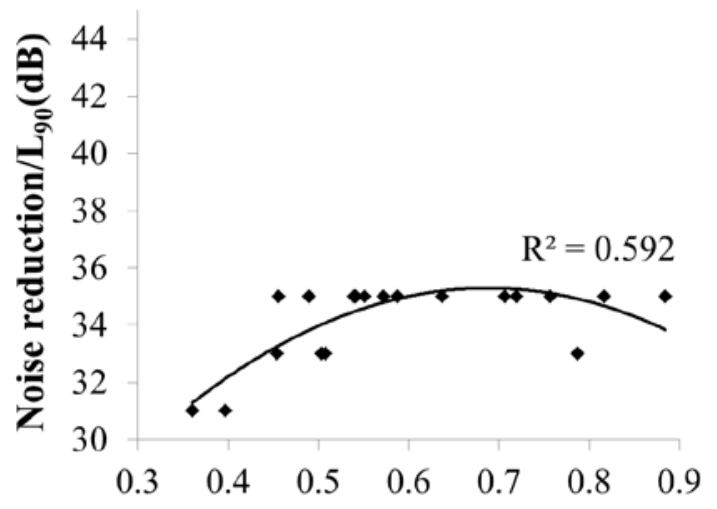

Building Surface Area to Plan Area Ratio

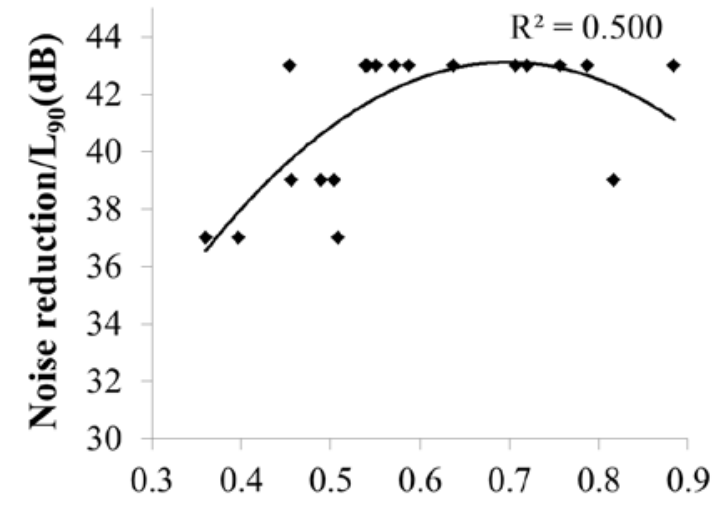

Building Surface Area to Plan Area Ratio

(b) $3150 \mathrm{~Hz}$

(a) $630 \mathrm{~Hz}$

Fig. 8. Relationships between $\mathrm{L}_{90}$ in open areas and the Building Surface Area to Plan Area Ratio.

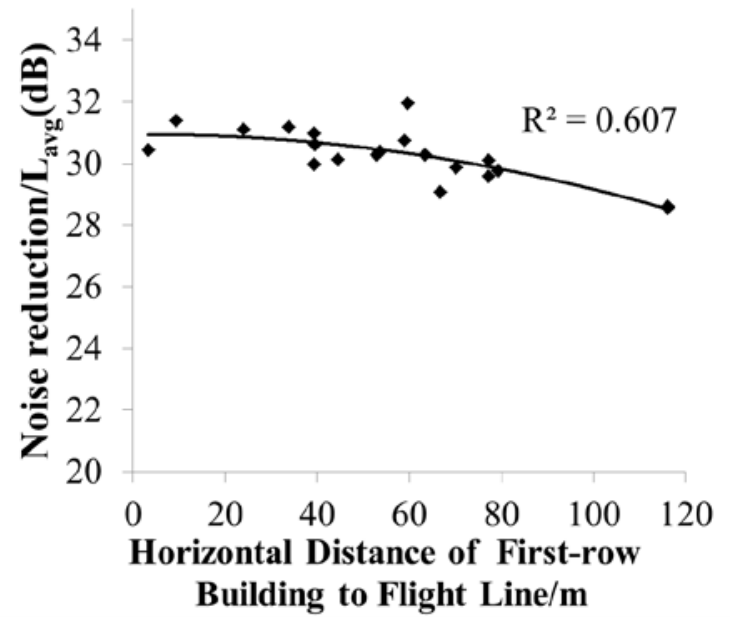

(a) $\mathrm{L}_{\text {avg }}$ at $1600 \mathrm{~Hz}$

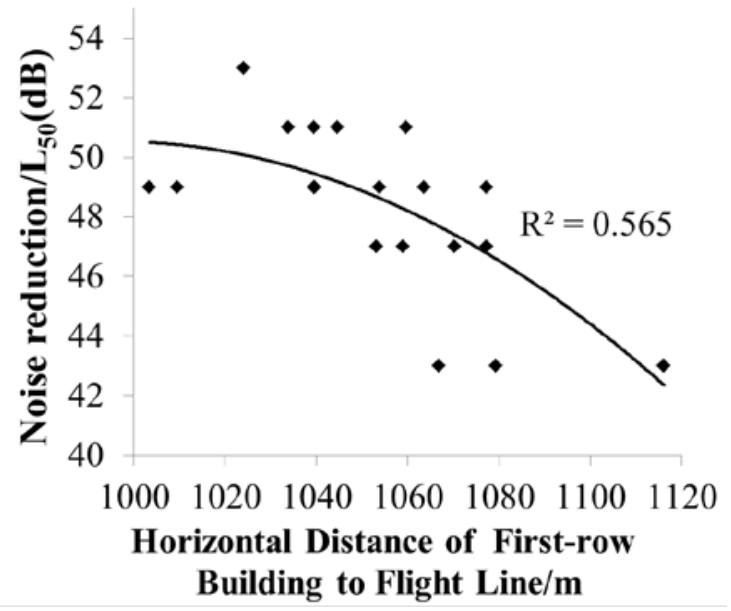

(b) $\mathrm{L}_{50}$ at $630 \mathrm{~Hz}$

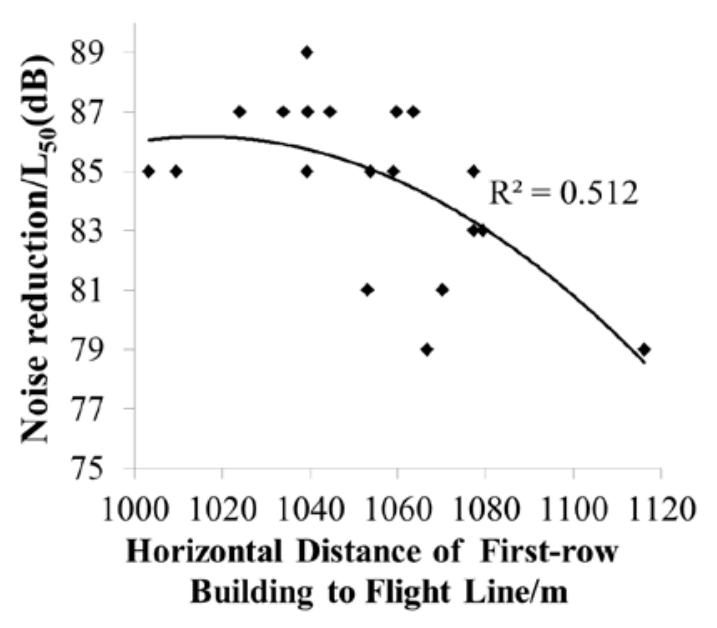

(c) $\mathrm{L}_{50}$ at $3150 \mathrm{~Hz}$

Fig. 9. Relationships between acoustic indices in open areas and the Horizontal Distance of First-row Building to Flight Path. 
To overview the above results about the correlations between urban morphological parameters and acoustic indices, Table 7 shows the number of correlations according to the acoustic indices, and Table 8 gives the number of correlations according to the horizontal distances between site and flight path. It can be seen from Table 7 that $\mathrm{L}_{90}(15)$ and $\mathrm{L}_{\text {avg }}$ (13) in open areas are more correlated to urban morphological parameters than $\mathrm{L}_{10}$, which indicates that control of urban morphological parameters can benefit aircraft noise attenuation for the relatively quiet areas and the whole area of a given site. Table 8 shows that when the distance is $1000 \mathrm{~m}$, urban morphology has greater influence on aircraft noise attenuation, both on façades and in open areas. Overall, two parameters, BFAI (14) and HDFBFP (17) have more correlations than the others.

Table 7. The number of correlations between urban morphological parameters and acoustic indices, according to the acoustic indices $\mathrm{L}_{10}, \mathrm{~L}_{50}, \mathrm{~L}_{90}$ and $\mathrm{L}_{\text {avg, }}$, both on façades and in open areas.

\begin{tabular}{|c|c|c|c|c|c|c|c|c|c|}
\hline \multirow{2}{*}{$\begin{array}{l}\text { Urban } \\
\text { Morphological } \\
\text { Parameters } \\
\end{array}$} & \multicolumn{4}{|c|}{ Open areas } & \multicolumn{4}{|c|}{ Façades } & \multirow{2}{*}{ Total } \\
\hline & $L_{10}$ & $\overline{L_{50}}$ & $\overline{L_{90}}$ & $\overline{L_{\text {avg }}}$ & $L_{10}$ & $\overline{L_{50}}$ & $L_{90}$ & $\overline{L_{\text {avg }}}$ & \\
\hline BPAF & 0 & 0 & 0 & 0 & 0 & 0 & 0 & 0 & 0 \\
\hline$C A R$ & 0 & 0 & 5 & 1 & 0 & 1 & 1 & 1 & 9 \\
\hline BSAPAR & 1 & 0 & 4 & 1 & 1 & 1 & 1 & 0 & 9 \\
\hline BFAI & 1 & 0 & 4 & 4 & 1 & 2 & 0 & 2 & 14 \\
\hline HWR & 0 & 0 & 0 & 0 & 0 & 0 & 0 & 0 & 0 \\
\hline HDFBFP & 1 & 5 & 2 & 7 & 2 & 0 & 0 & 0 & 17 \\
\hline Total & 3 & 5 & 15 & 13 & 4 & 4 & 2 & 3 & 49 \\
\hline
\end{tabular}

Table 8. The number of correlations between urban morphological parameters and acoustic indices, according to the horizontal distance between site and flight path, at $0 \mathrm{~m}, 300 \mathrm{~m}$ and $1000 \mathrm{~m}$, both on façades and in open areas.

\begin{tabular}{|c|c|c|c|c|c|c|c|}
\hline \multirow{2}{*}{$\begin{array}{l}\text { Urban } \\
\text { Morphological } \\
\text { Parameters } \\
\end{array}$} & \multicolumn{3}{|c|}{ Open areas } & \multicolumn{3}{|c|}{ Façades } & \multirow{2}{*}{ Total } \\
\hline & $0 m$ & $300 m$ & $1000 m$ & $0 m$ & $300 m$ & $1000 m$ & \\
\hline BPAF & 0 & 0 & 0 & 0 & 0 & 0 & 0 \\
\hline$C A R$ & 2 & 1 & 3 & 0 & 0 & 3 & 9 \\
\hline BSAPAR & 3 & 1 & 2 & 0 & 0 & 3 & 9 \\
\hline BFAI & 3 & 0 & 6 & 1 & 0 & 4 & 14 \\
\hline HWR & 0 & 0 & 0 & 0 & 0 & 0 & 0 \\
\hline HDFBFP & 3 & 5 & 7 & 0 & 2 & 0 & 17 \\
\hline Total & 11 & 7 & 18 & 1 & 2 & 10 & 49 \\
\hline
\end{tabular}

\section{Conclusions}

This study aims to explore whether and how mesoscale urban morphology of low-density built-up areas influence the spatial noise level attenuation of flyover aircrafts. Six urban morphological parameters 
have been selected and developed in the study. The effects of horizontal flight path distance to site and flight altitude on aircraft noise attenuation are both considered.

The largest difference and variance of aircraft noise level attenuation are at $1000 \mathrm{~m}$, among the five horizontal flight path distances to site, i.e. $0 \mathrm{~m}, 100 \mathrm{~m}, 300 \mathrm{~m}, 600 \mathrm{~m}$ and $1000 \mathrm{~m}$. Sound reflections by buildings reduce the influence of urban morphology on noise attenuation. Compared with the distances of $0 \mathrm{~m}$ and $300 \mathrm{~m}$, the acoustic indices have more correlations with the urban morphological parameters at $1000 \mathrm{~m}$. The increase from $200 \mathrm{ft}$ to $400 \mathrm{ft}$ in flight altitude generally does not benefit the noise attenuation significantly.

The façades have higher noise attenuation than open areas, but the variances of the acoustic indices on façades, including $\mathrm{L}_{10}, \mathrm{~L}_{50}, \mathrm{~L}_{90}$ and $\mathrm{L}_{\text {avg }}$, are lower, and their correlations with the urban morphological parameters are less. In other words, urban morphology plays a more important role on aircraft noise attenuation for open areas than for façades. Moreover, the control of urban morphological parameters can benefit aircraft noise level attenuation more in quiet open areas and the whole area, rather than noisy open areas.

The urban morphological parameters tend to have considerable correlations with flyover aircraft noise attenuation in this study. Compared with the sound source location independent morphological parameters, the sound source dependent parameters may have greater influence. The general tendency is that the Building Frontal Area Index (BFAI) and Horizontal Distance of First-row Building to Flight Path (HDFBFP) correlate with noise attenuation most, while Building Plan Area Fraction (BPAF) and Height-to-Width Ratio (HWR) hardly influence the noise attenuation. The noise level attenuation in terms of $\mathrm{L}_{90}$ in open areas tends to increase with the increase of Complete Aspect Ratio (CAR) and then stays stable after CAR reaches approximately 1.4. The noise level attenuation in terms of $L_{90}$ in open areas has a tendency to increase when the Building Surface Area to Plan Area Ratio (BSAPAR) increase before approximately 0.7 and it then decreases. The noise attenuation in terms of $\mathrm{L}_{50}$ and $\mathrm{L}_{\mathrm{avg}}$ shows a constant upward tendency when HDFBFP decreases.

\section{Acknowledgements}

The authors are indebted to D. Krijnders and H. Woertche in INCAS $^{3}$ for their kindly support and useful discussion. This project is supported by the Northern Netherlands Provinces and funded by the European Union, European Fund for Regional Development and the Dutch Ministry of Economic Affairs, Peaks in the Delta. 


\section{References:}

[1] Morrell P, Lu CHY. Aircraft noise social cost and charge mechanisms - a case study of Amsterdam Airport Schiphol. Transportation Research Part D: Transport and Environment 2000; 5(4):305-20.

[2] Babisch W, Houthuijs D, Pershagen G, Cadum E, Katsouyanni K, Velonakis M, Dudley ML, Marohn HD, Swart W, Breugelmans O, Bluhm G, Selander J, Taglianti FV, Pisani S, Haralabidis A, Dimakopoulou K, Zachos I, Järup L. Annoyance due to aircraft noise has increased over the yearsResults of the HYENA study. Environment International 2009; 35(8): 1169-76.

[3] Vogiatzis K. Airport environmental noise mapping and land use management as an environmental protection action policy tool: The case of the Larnaka International Airport (Cyprus). Science of the Total Environment 2012; 424: 162-73.

[4] Klaeboe R. Aircraft noise annoyance in recreational areas after changes in noise exposure: comments on Krog and Engdahl. JASA 2004; 116: 323-33.

[5] Speakman JD. Noisemap-the USAF's computers program for predicting noise exposure around an airport. Inter-noise1980 (2): 823-6.

[6] Zaporozhets OI, Tokarev VI. Aircraft noise modelling for environmental assessment around airports. Applied Acoustics 1998; 55(2): 99-127.

[7] Khardia S, Abdallahb L. Optimization approaches of aircraft flight path reducing noise: Comparison of modeling methods. Applied Acoustics 2012; 73(4): 291-301.

[8] DataKustik. Calculation and Prediction of Aircraft Noise, <http://www.datakustik.com/index.php? id $=1352 \& L=1>$, accessed on 30 April 2013.

[9] ATAC. Integrated Noise Model (INM), <http://www.atac.com/inm.html> accessed on 30 April 2013.

[10] Vogiatzis K. Airport environmental noise mapping and land use management as an environmental protection action policy tool. The case of the Larnaka International Airport (Cyprus). Science of the Total Environment 2012; 424: 152-73.

[11] Asensio C, Pavón I, Ruiz M, Pagán R, Recuero M. Aircrafts' taxi noise. Sound power level and directivity frequency band results. Applied Acoustics 2009. 70: 986-1008.

[12] Ismail MR, Oldham DJ. The Effect of the Urban Street Canyon on the Noise from Low Flying Aircraft. Building Acoustics 2002; 9: 233-51.

[13] Kinney WA, Pierce AD, Rickley EJ. Helicopter noise experiments in an urban environment. JASA 1974; 56: 332-337.

[14] Pande L. Model study of aircraft noise reverberation in a city street. Dept. of Mechanical Engineering, Massachusetts Institute of Technology. Interim Rep. DOT-TSC-93;1972.

[15] Crooks MA, Langdon FJ. The effects of aircraft noise in schools around London airport. Journal of Sound and Vibration 1974; 34(2): 221-32.

[16] Sijtsma P, Stoker RW. Determination of Absolute Contributions of Aircraft Noise Components using Fly-Over Array Measurements. National Aerospace Laboratory NLR. Report NLR-TP-2004-167; 2004.

[17] Lavandier C, Barbot B, Terroir J, Schuette M. Impact of aircraft sound quality combined with the repetition of aircraft flyovers on annoyance as perceived activity disturbance in a laboratory context. Applied Acoustics 2011; 72(4); 169-76.

[18] Taylor SM. A path model of aircraft noise annoyance. Journal of Sound and Vibration 1984; 96(2): 243-60.

[19] Assen Municipality. Assen in cijfers, <http://assen.buurtmonitor.nl/> accessed on 30 April 2013.

[20] Klæboe R, Engelien E, Steinnes M. Context sensitive noise impact mapping. Applied Acoustics 2006; 67( 7): 620-42.

[21] Szulecki S, Zwerling E, Anderson C, Turpin B. Modeling with the use of the commercial software package CADNAA (Computer-Aided Noise Abatement) to estimate the probability of awakening associated with train horns. (A). JASA 2010; 127(3): 1764-64.

[22] McGowan EW. The effect of building reflections on the equivalent noise level $\left(\mathrm{L}_{\mathrm{eq}}\right)$ from traffic on Lake Shore Drive. JASA 2012; 132(3): 2085-85.

[23] DataKustik GmbH. Cadna/A for windows - user manual. Greifenberg 2006.

[24] Kang J. Urban sound environment. Taylor Francis, London; 2007.

[25] Huang J. Accuracy and Efficiency in Noise-Mapping. MSc dissertation, School of Architecture, 
University of Sheffield, UK, 2003.

[26] Tompsett R. Noise mapping - accuracy is our priority. Acoustics Bulletin 2002: 27(4), 9.

[27] Dutch government. Ruimtelijkeplannen.nl, <http://www.ruimtelijkeplannen.nl> accessed on 30 April 2013.

[28] Kadaster. TOP10NL, < http://www.kadaster.nl/window.html?inhoud=/top10nl/> accessed on 30 April 2013.

[29] Khardi S. An experimental analysis of frequency emission and noise diagnosis of commercial aircraft on approach. J. Acoustic Emission 2008; 26: 290-310.

[30] Wang B, Kang J. Effects of urban morphology on the traffic noise distribution through noise mapping: A comparative study between UK and China. Applied Acoustics 2011; 72: 556-68.

[31] Adolphe L. A simplified model of urban morphology: application to an analysis of the environmental performance of cities. Environment and Planning B: Planning and Design 2001; 28 (2): 183-200.

[32] Xie X, Huang Z, Wang J. The impact of urban street layout on local atmospheric environment. Building and Environment 2006, 41, 1352-1363.

[33] Ng E, Yuan C, Chen L, Ren C, Fung JCH. Improving the wind environment in high-density cities by understanding urban morphology and surface roughness: A study in Hong Kong. Landscape and Urban Planning 2011; 101: 59-74.

[34] Salomons EM, Pont MB. Urban traffic noise and the relation to urban density, form, and traffic elasticity. Landscape and Urban Planning 2012; 108 (1): 2-16.

[35] Raydan D, Steemers K. Environmental urban design, Santamouris M. ed. Environmental Design of Urban Buildings: An Integrated Approach. Earthscan, London; 2006.

[36] Voogt J, Oke T. Complete urban surface temperatures. J. Appl. Met. 1997; 36: 1117-32.

[37] Burian SJ, Han, WS, Brown MJ. Morphological analyses using 3D building databases: Oklahoma City, Oklahoma. LA-UR-05-1821, Los Alamos National Laboratory, Los Alamos, New Mexico; 2005. 